\title{
STRATEGI BISNIS PT XYZ PADA INDUSTRI FUEL RETAIL DI DKI JAKARTA DAN BANTEN
}

\author{
BUSINESS STRATEGY OF PT XYZ IN DKI JAKARTA \& BANTEN FUEL RETAIL INDUSTRY
}

\author{
Rafdi Dzulfikar Ramdhani*)1, Lukman M. Baga**), Popong Nurhayati*) \\ ${ }^{*}$ Sekolah Bisnis IPB University, \\ Jl. Raya Padjajaran 16151 Bogor, Indonesia. \\ ${ }^{* *}$ Departemen Agribisnis, Fakultas Ekonomi dan Manajemen, IPB University, \\ Jl. Agatis Kampus IPB Darmaga 16680, Bogor, Indonesia
}

\begin{abstract}
P T X Y Z$ is a company engaged in the retail business of Pertamina's products. PT XYZ needs to have the right alternative strategy to respond the slowdown in fuel sales growth and the growth of foreign gas stations in DKI Jakarta \& Banten fuel retail industry. This research aims to analyze internal and external factors that affect the business of PT XYZ and develop appropriate business strategies for PT XYZ. Some of the analytical tools used in this research are VRIO analysis, Porter's Five Forces, PESTEL, Internal-External matrix, and SWOT analysis. The method of collecting data is carried out through observation, interviews, questionnaires, and literature studies. Interviewees in this study consisted of internal parties that government policies in PT XYZ and external parties, namely the BPH Migas committee. Based on the results of the identification of the internal and external environment, there are several internal factors consisting of 7 strengths and 5 weaknesses of the company, as well as strategic external factors consisting of 4 opportunities and 4 threats that affect the business of PT XYZ. PT XYZ is in quadrant V in the IE matrix, so that there are 9 alternative strategies that can be applied to PT XYZ's business, consisting of 6 product development strategies and 3 market penetration strategies.
\end{abstract}

Keywords: alternative strategy, PESTEL, Porter's Five Forces, SWOT, VRIO

\begin{abstract}
Abstrak: PT XYZ merupakan perusahaan yang bergerak di bidang usaha ritel produk Pertamina. PT XYZ perlu memiliki strategi alternatif yang tepat untuk merespons perlambatan pertumbuhan penjualan BBM dan pertumbuhan SPBU asing pada industri fuel retail di DKI Jakarta dan Banten. Penelitian ini bertujuan menganalisis faktor-faktor internal dan eksternal yang memengaruhi bisnis PT XYZ dan menyusun strategi bisnis yang tepat untuk PT XYZ. Beberapa alat analisis yang digunakan dalam penelitian ini adalah analisis VRIO, Porter's Five Forces, PESTEL, matriks Internal-Eksternal, dan analisis SWOT. Metode pengambilan data dilakukan melalui observasi, wawancara, kuesioner dan studi literatur. Narasumber dalam penelitian ini terdiri dari pihak internal perusahaan yang mengatur kebijakan di PT XYZ dan pihak eksternal yaitu komite BPH Migas. Berdasarkan hasil identifikasi lingkungan internal dan eksternal terdapat beberapa faktor internal yang terdiri dari 7 kekuatan dan 5 kelemahan perusahaan yang dimiliki PT XYZ, serta didapatkan faktor eksternal strategis yang terdiri dari 4 peluang dan 4 ancaman yang memengaruhi bisnis PT XYZ. PT XYZ berada pada kuadran V dalam matriks IE, sehingga didapatkan 9 strategi alternatif yang dapat diterapkan untuk bisnis PT XYZ, terdiri dari 6 strategi pengembangan produk dan 3 strategi penetrasi pasar.
\end{abstract}

Kata kunci: strategi alternatif, PESTEL, Porter's Five Forces, SWOT, VRIO

\footnotetext{
${ }^{1}$ Corresponding author:

Email: rafdidr@gmail.com
} 


\section{PENDAHULUAN}

Bahan Bakar Minyak (BBM) merupakan salah satu unsur vital yang diperlukan dalam pelayanan kebutuhan energi di suatu negara. Kebutuhan BBM dalam negeri diprediksi akan semakin meningkat seiring dengan tren pertumbuhan jumlah kendaraan bermotor di Indonesia yang meningkat setiap tahunnya seperti ditunjukan pada Gambar 1.

Hal ini membuat industri fuel retail di Indonesia menjadi sangat menarik bagi para investor lokal maupun asing. Para investor lokal maupun asing akan berlomba-lomba membangun Stasiun Pengisian Bahan Bakar Umum (SPBU) untuk memenuhi kebutuhan Bahan Bakar Minyak (BBM) di Indonesia. Apalagi sejak disahkanya Undang-undang nomor 5 tahun 1999 tentang larangan praktek monopoli dan persaingan usaha tidak sehat, investor asing mulai berani masuk ke industri fuel retail Indonesia. Shell mulai membangun SPBU di Indonesia pada November 2005. Disusul oleh Petronas pada Desember 2005, walaupun Petronas akhirnya memilih mundur dari industri fuel retail Indonesia pada Agustus 2012. Selanjutnya ada Total yang masuk pada Maret 2009. SPBU asing yang terbaru adalah Vivo dan $B P$ $A K R$ yang mulai masuk ke Indonesia masing-masing pada tahun Oktober 2017 dan Mei 2019. Konsumen kini memliki banyak pilihan sejak masuknya SPBU asing di Indonesia. Pertumbuhan jumlah SPBU Asing yang cepat membuat pertumbuhan volume penjualan BBM di SPBU PT XYZ menjadi lambat seperti ditunjukan pada Gambar 2. PT XYZ perlu memiliki strategi yang tepat untuk merespons perlambatan pertumbuhan penjualan BBM dan pertumbuhan SPBU asing pada industri fuel retail di DKI Jakarta \& Banten.
Kajian akademik dan penelitian pada industri fuel retail sudah banyak dilakukan, namun kebanyakan masih terbatas pada pembahasan mengenai pengaruh perubahan harga dan regulasi penjualan BBM (Bumpass et al. 2015; Haucap et al. 2017; Yilmazkuday dan Yilmazkuday, 2019; Davis et al. 2019). Perencanaan strategi bisnis untuk menghadapi industri fuel retail di DKI Jakarta \& Banten dapat menjadi kebaruan dalam penelitian ini.

Penelitian ini bertujuan menganalisis faktor-faktor internal dan eksternal yang memengaruhi bisnis PT XYZ. Selanjutnya, merekomendasikan strategi bisnis yang tepat untuk PT XYZ. Penelitian ini dibatasi pada formulasi dan rekomendasi strategi bisnis PT XYZ dan difokuskan pada bisnis SPBU di industri fuel retail di DKI Jakarta \& Banten. Harapanya PT XYZ memiliki strategi bisnis yang tepat untuk mengahadapi industri fuel retail di DKI Jakarta \& Banten.

\section{METODE PENELITIAN}

Penelitian ini dilaksanakan di PT XYZ yang berlokasi di Jakarta pusat dan dilakukan pada Bulan Februari - Juni 2020. Penelitian ini dilakukan dengan metode penelitian campuran (mixed method) yaitu menggabungkan antara metode kuantitatif dan kualitatif sehingga data yang diperoleh menjadi lebih komprehensif, reliable, valid, dan objektif (Sugiyono, 2017). Jenis data yang dikumpulkan terdiri atas dua jenis data, yaitu data primer dan data sekunder.

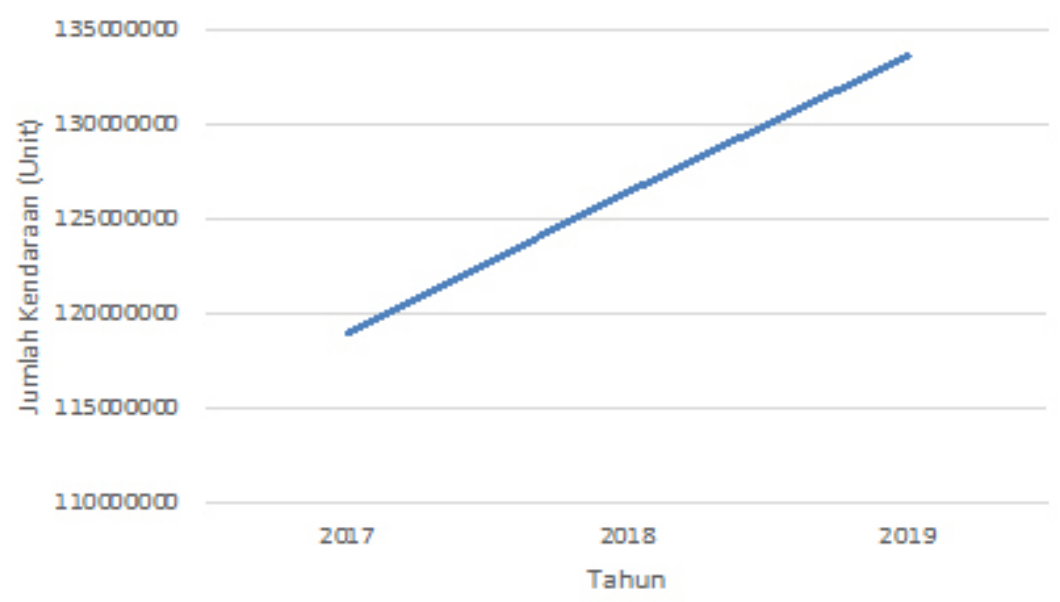

Gambar 1. Jumlah kendaraan bermotor di Indonesia tahun 2017-2019 (BPS, 2019) 


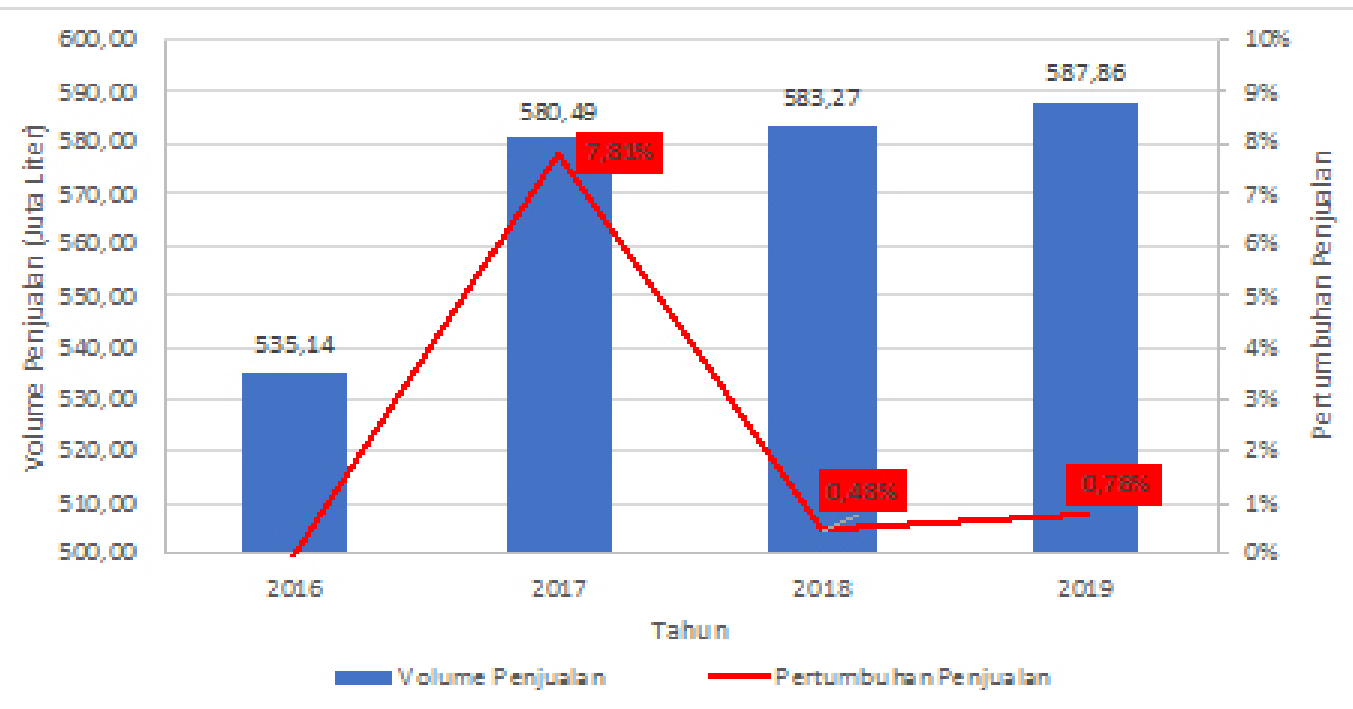

Gambar 2. Tren penjualan SPBU PT XYZ tahun 2016-2019

Data primer diperoleh dari hasil observasi, kuesioner, dan wawancara mendalam dengan narasumber internal yang terdiri dari VP of Fuel retail, Sales Area Manager II, Ast. Manager Sales Support, Business Unit Head PT XYZ dan narasumber eksternal yaitu komite BPH Migas. Data sekunder diperoleh dari dokumen yang dimiliki oleh pihak perusahaan dan instansi terkait serta studi pustaka.

Penelitian ini dimulai dengan melakukan analisis lingkungan internal dan eksternal PT XYZ sesuai dengan teori dan observasi kondisi riil dilapangan. Hasil analisis berupa faktor internal yang terdiri dari kekuatan dan kelemahan dan faktor eksternal yang terdiri dari peluang dan ancaman dikonfirmasi kepada narasumber melalui wawancara mendalam. Faktor Internal yang telah didapatkan selanjutnya dianalisis menggunakan analisis VRIO (Valuable, Rare, Inimitable, Organized) (Knott, 2009). Faktor eksternal dianalisis menggunakan metode analisis Porter's Five Forces untuk melihat persaingan antar industry (Porter, 1998). Sedangkan untuk melihat kondisi eksternal secara makro digunakan analisis PESTEL (Yüksel, 2012; Gregoric, 2014).

Hasil wawancara mendalam dengannarasumbertersebut berupa data kualitatif yaitu identifikasi faktor internal dan eksternal perusahaan. Selanjutnya, dipilih isu-isu strategis dari berbagai faktor internal dan eksternal. Isu strategis adalah isu yang apabila tidak ditangani akan berdampak besar pada perusahaan di masa yang akan datang. Isu strategis dipilih berdasarkan pertimbangan bersama dengan narasumber internal perusahaan. Isuisu strategis yang telah dipilih kemudian dianalisis secara kuantitatif dengan pemberian bobot dan peringkat pada masing-masing faktor menggunakan Evaluasi Faktor Internal (Matriks IFE) dan Evaluasi Faktor Eksternal (Matriks EFE). Pemberian bobot dan peringkat dilakukan dengan memberikan kuesioner kepada narasumber internal PT XYZ. Hasil pembobotan merupakan hasil rata-rata yang didapat dari keempat narasumber. Bobot dari tiap narasumber dihasilkan melalui perbandingan setiap faktor dengan metode paired comparison. Sementara untuk nilai peringkat yang diperoleh merupakan nilai yang dipilih terbanyak oleh responden.

Selanjutnya dilakukan penyusunan Matriks Internal Eksternal (IE) sehingga diperoleh posisi perusahaan dan langkah yang seharusnya dilakukan dimasa yang akan datang. Matriks SWOT digunakan untuk membuat beberapa strategi alternatif yang berasal dari kombinasi analisis internal dan eksternal yang telah diperoleh, seperti dilakukan oleh Wicaksono (2020). Strategi alternatif yang dihasilkan dituangkan dalam impikasi manajerial berupa rekomendasi strategi yang dijabarkan dalam rencana kegiatan strategik. Secara singkat, kerangka pemikiran penelitian dapat dilihat pada Gambar 3.

\section{HASIL}

\section{Analisis Faktor Internal}

Berdasarkan hasil analisis VRIO, didapatkan 9 faktor internal merupakan keunggulan kompetitif berkelanjutan (Sustained Competitive Advantage) 
perusahaan, 2 faktor internal merupakan keunggulan kompetitif sementara (Temporary Competitive Advantage), dan 9 faktor internal merupakan paritas kompetitif (Competitive Parity) yang menjadi kekuatan PT XYZ, dan 7 faktor internal merupakan peluang yang tidak dimanfaatkan (Missed Opportunity) yang menjadi kelemahan PT XYZ. Selanjutnya dipilih faktor-faktor internal strategis melalui wawancara narasumber internal.

\section{Kekuatan}

\section{Lokasi dan jumlah SPBU}

PT XYZ memiliki 46 SPBU yang tersebar di DKI Jakarta \& Banten. Lokasinya pun sangat stretegis, berada di jalan utama. Jumlah dan lokasi SPBU yang strategis menjadi kekuatan bagi PT XYZ.

\section{Brand Pertamina}

Posisi Pertamina sebagai Badan Usaha Milik Negara (BUMN) menjadi keuntungan tersendiri. Bertahuntahun menjalani bisnis secara monopoli di industri fuel retail membuat brand SPBU Pertamina menjadi sangat kuat di masyarakat. PT XYZ sebagai operator
SPBU Pertamina dapat memanfaatkan faktor ini untuk menjadi kekuatan perusahaan dalam bersaing di industri fuel retail di DKI Jakarta \& Banten.

Sistem Pembayaran menggunakan MyPertamina dan RFID

MyPertamina dan Radio Frequency Identification (RFID) merupakan sistem pembayaran nontunai yang tersedia di SPBU PT XYZ. MyPertamina adalah aplikasi layanan keuangan digital dari Pertamina. Sedangkan RFID hanya dapat dilakukan di SPBU PT

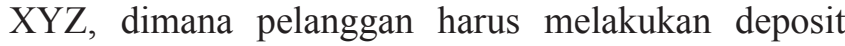
terlebih dahulu. Metode pembayaran RFID memiliki kelebihan yaitu fitur keamanannya yang baik. Kedua sistem pembayaran ini dapat menjadi kekuatan bagi PT $\mathrm{XYZ}$.

Tersedia car wash di beberapa SPBU

SPBU PT XYZ telah bekerjasama dengan Autoglaze untuk menyediakan car wash di SPBU. Hingga Maret 2020, terdapat 12 SPBU PT XYZ yang tersedia fasilitas car wash. Hal ini dapat menjadi kekuatan bagi PT XYZ karena belum ada SPBU pesaing di DKI Jakarta \& Banten yang memiliki fasilitas car wash di SPBU.

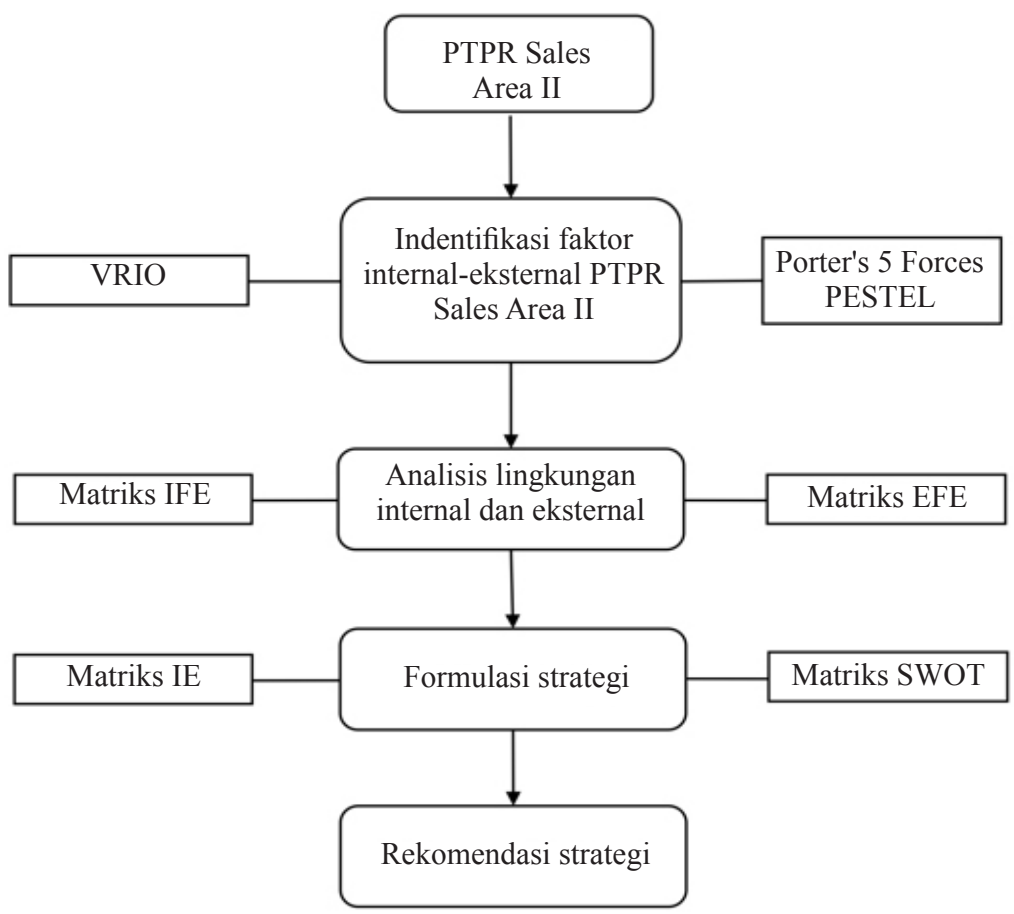

Gambar 3. Kerangka pemikiran penelitian 
SPBU PT XYZ diaudit oleh pihak eksternal setiap bulanya. Ada 5 elemen yang dinilai, yaitu: Well Trained \& Motivated Staff (WTMS), Quality \& Quantity Assurance (Q\&Q), Well Mantained Equipment \& Facility (WME\&F), Consistent Phisycal Format, aligned with Overall Retail Strategy (CPF), dan Comprehensive Product Offering (CPO). Audit yang dilakukan ini menjamin Quality \& Quantitiy (QnQ) dari SPBU PT XYZ tetap terjaga dengan baik. Jaminan Quality \& Quantitiy (QnQ) yang baik dapat menjadi kekuatan bagi PT XYZ.

\section{Modal (equity) dari PT Pertamina (Persero)}

Sebagai anak perusahaan dari PT Pertamina (Persero), PT XYZ diberi modal (equity) setiap tahunya untuk anggaran belanja perusahaan. Modal ini dapat digunakan untuk investasi atau memperkuat asset perusahaan. Hal ini dapat menjadi kekuatan bagi PT XYZ untuk memanfaatkan modal dalam pengembangan bisnisnya.

Kebijakan single margin dari Pertamina (Persero)

Sebagai perusahaan yang mengelola SPBU Pertamina, PT XYZ diberi margin khusus yang dikenal sebagai single margin. Single margin merupakan suatu nilai margin yang diberikan oleh PT Pertamina (Persero) untuk setiap liter dan setiap jenis BBM yang dijual bergantung kepada dua kondisi, yaitu (1) Jumlah SPBU yang lolos standar Pasti Pas maupun Pasti Prima, dan (2) Komposisi penjualan BBM subsidi dan BBM nonsubsidi. Semakin banyak jumlah SPBU yang lolos standar Pasti Pas maupun Pasti Prima dan semakin tinggi penjualan BBM non-subsidi, maka nilai single margin yang diterima oleh PT XYZ akan maksimal. Hal ini menjadikan kebijakan single margin menjadi kekuatan bagi PT XYZ yang harus dimaksimalkan.

\section{Kelemahan}

Lemahnya pengelolaan convenience store

Convenience store dengan merk dagang Bright Store merupakan convenience store yang ada di SPBU PT XYZ. Ketidakmampuan pengelolaan convenience store yang baik membuat Bright Store merugi, sehingga keuntungan dari menjual BBM digunakan untuk menutupi kerugian ini. Hal ini menjadi kelemahan bagi PT XYZ.
Budaya kerja perusahaan kurang baik

Budaya dalam bekerja di PT XYZ masih perlu dilakukan pengembangan. Budaya kolaborasi masih kurang karena masih terlalu mementingkan ego sektoral masingmasing fungsi sehingga seringkali disibukan dengan permasalahan Internal. Hal ini menjadi kelemahan bagi PT XYZ.

Kapabilitas pekerja kurang baik

Hasil wawancara dengan narasumber internal, didapatkan bahwa kapabilitas pekerja PT XYZ kurang baik. Ada beberapa pekerja yang ditempatkan tidak sesuai dengan kemampuanya sehingga menghambat pekerjaanya. Divisi Human Resources juga belum memiliki talent pool untuk melakukan mapping pekerja. Hal ini menjadi kelemahan bagi PT XYZ.

Organisasi yang tidak efektif

Dalam struktur organisasi PT XYZ, ada beberapa posisi yang kosong (vacant). Beberapa pekerjaan yang seharusnya menjadi beban 2 pekerja namun dilakukan oleh hanya 1 pekerja. Hal ini tentu menghambat jalanya perusahaan dan dapat menjadi kelemahan bagi PT XYZ.

Lemahnya kemampuan collecting piutang

Kemampuan collecting piutang yang dimiliki oleh PT XYZ sangat kurang, hal ini ditandai dengan nilai piutang yang besar. Berdasarkan laporan keuangan tahun 2018, piutang lain-lain pada tahun 2018 berada pada nilai Rp7.550.089.071,00, padahal pada tahun 2017 nilai piutang tersebut adalah Rp3.321.312.567,00. Apabila kemampuan ini tidak ditingkatkan maka akan menganggu kelancaran arus kas perusahaan. Maka dari itu kemampuan PT XYZ dalam melakukan collecting piutang menjadi kelemahan perusahaan.

\section{Evaluasi Faktor Internal}

Evaluasi faktor internal (IFE) digunakan untuk mengukur kondisi internal perusahaan. Konndisi internal mencakup segi kekuatan maupun kelemahan perusahaan. Adapun hasil evaluasi faktor internal terdapat pada Tabel 1. Berdasarkan evaluasi yang telah dilakukan, didapatkan total skor internal sebesar 2,69 , dimana skor tersebut lebih besar dari skor ratarata yaitu 2,50. Hal tersebut mengindikasikan bahwa 
perusahaan kuat secara internal. Perusahaan mampu memanfaatkan kekuatan yang dimiliki dan mampu mengatasi kelemahan yang ada.

\section{Analisis Faktor Eksternal}

Analisis lingkungan eksternal digunakan untuk mengidentifikasi faktor-faktor strategis berupa peluang dan ancaman bagi PT XYZ. Penelitian ini menggunakan analisis Porter's Five Forces dan analisis PESTEL (Political, Economic, Social, Technological, Environment, Legal). Analisis tersebut diaplikasikan melalui in depth interview dengan narasumber internal dan eksternal yang menghasilkan faktor eksternal yang dapat dijadikan peluang dan ancaman.

\section{Peluang}

Potensi pengembangan produk substitusi

Salah satu produk pengganti dari BBM adalah Bahan Bakar Gas (BBG). Keunggulan BBG ini adalah harganya yang lebih murah dari BBM, nilai oktana yang tinggi, serta ramah lingkungan. Namun, BBG memiliki kelemahan seperti harga converter kit yang mahal, investasi pembangunan Stasiun Pengisian Bahan Bakar Gas (SPBG) dan jaringan pipa gas yang mahal, dan belum terbiasanya masyarakat menggunakan BBG. Selain BBG, potensi produk pengganti dari BBM yang lainnya adalah energi listrik. Hanya memang untuk populasi kendaraan listrik pertumbuhanya masih belum terlalu masif. Dikutip dari Kompas.com, hingga Januari 2020 jumlah kendaraan listrik yang terdaftar di DKI Jakarta baru 699 unit. Hal ini menunjukan bahwa potensi pengembangan produk substitusi tidak menjadi ancaman dan dapat menjadi peluang bagi PT XYZ.

Daya tawar pembeli/konsumen

Dalam industri fuel retail, pembeli tidak memiliki kemampuan untuk mengendalikan harga karena BBM merupakan kebutuhan primer masyarakat dan bersifat inelastis (Ma'ruf, 2005). Konsumen hanya dapat menawar kualitas yang mereka inginkan. Hal ini menjadi peluang bagi PT XYZ yang telah menggunakan standar Pertamina Pasti Pas maupun Pasti Prima untuk menjamin kualitas pelayanan kepada konsumen. Konsumen dilayani dengan Standar Operasional Prosedur (SOP) yang telah ditetapkan.

Daya tawar pemasok

BBM yang dijual oleh SPBU PT XYZ dipasok oleh pemasok tunggal yaitu PT Pertamina (Persero) melalui Terminal Bahan Bakar Minyak (TBBM) Plumpang dan Tanjung Gerem. Jika terjadi masalah suplai BBM dari TBBM Plumpang dan Tanjung Gerem, maka suplai BBM dapat dipenuhi oleh 5 TBBM lainya milik PT Pertamina (Persero) yang berada di Jawa Barat yaitu TBBM Padalarang, Ujung Berung, Balongan, Cikampek, dan Tasikmalaya. Maka dari itu daya tawar pemasok merupakan peluang bagi PT XYZ.

Tabel 1. Matriks Internal Factor Evaluation (IFE) PT XYZ

\begin{tabular}{lccc}
\hline Faktor Internal Strategis & Bobot & Peringkat & Skor \\
\hline Kekuatan (Strength) & & & \\
Lokasi dan jumlah SPBU & 0,09 & 4 & 0,38 \\
Brand Pertamina & 0,09 & 3 & 0,28 \\
Sistem pembayaran menggunakan MyPertamina dan RFID & 0,09 & 3 & 0,27 \\
Tersedia car wash di beberapa SPBU & 0,07 & 3 & 0,22 \\
Jaminan Quality \& Quantitiy (QnQ) & 0,08 & 4 & 0,30 \\
Modal (equity) dari PT Pertamina (Persero) & 0,07 & 4 & 0,29 \\
Kebijakan single margin dari PT Pertamina (Persero) & 0,10 & 4 & 0,38 \\
Kelemahan (Weakness) & & & \\
Lemahnya pengelolaan convenience store & 0,09 & 1 & 0,09 \\
Budaya kerja perusahaan kurang baik & 0,08 & 2 & 0,17 \\
Kapabilitas pekerja kurang baik & 0,07 & 2 & 0,14 \\
Organisasi yang tidak efektif & 0,08 & 1 & 0,08 \\
Lemahnya kemampuan Collecting piutang & 0,08 & 1 & 0,08 \\
\hline Total Skor IFE & 2,69 & & \\
\hline
\end{tabular}




\section{Sinergi Badan Usaha Milik Negara (BUMN)}

Sinergi BUMN merupakan suatu program kerja sama diantara BUMN maupun anak usahanya untuk bersama-sama dapat meningkatkan nilai tambah perusahaan dan termasuk untuk kepentingan negara dan masyarakat. PT XYZ sebagai anak perusahaan dari PT Pertamina (Persero) memiliki peluang sangat besar untuk memanfaatkan program ini. PT XYZ dapat memanfaatkan program ini sebagai peluang untuk menambah jumlah pelanggan BBM Businnes to Businnes (B2B).

Tingkat pertumbuhan ekonomi

Pertumbuhan ekonomi suatu negara dapat diukur dengan Produk Domestik Bruto (PDB). PDB merupakan jumlah produksi barang dan jasa yang dihasilkan suatu negara dalam periode waktu tertentu. Pertumbuhan ekonomi Indonesia pada tahun 20142019 ditunjukan pada Gambar 4. Didapatkan bahwa rata-rata pertumbuhan ekonomi Indonesia tahun 20142019 hanya sebesar 5\%. Dari data tersebut disimpulkan bahwa nilai konsumsi/daya beli masyarakat bertumbuh namun tidak terlalu pesat. Pertumbuhan ekonomi ini dapat menjadi peluang bagi PT XYZ karena daya beli masyarakat tetap bertumbuh.

\section{Industri 4.0}

Istilah Industri 4.0 yang juga dikenal sebagai Fourth industrial Revolution (4IR) pertama kali diluncurkan pada tahun 2011 di Jerman pada acara Hannover Fair (Ghobakhloo, 2018). Pada aspek teknologi, industri 4.0 mendorong ditemukanya berbagai teknologi canggih yang bersifat disruptif seperti cloud computing, virtual reality, big data analytics, automation, dan Internet of Things (IoT) (Frederico et al. 2019). Berbagai teknologi ini tentunya akan berpengaruh pada berbagai lini bisnis termasuk bisnis di industri fuel retail. PT XYZ harus dapat memanfaatkan peluang perkembangan teknologi ini dan menerapkanya ke dalam bisnisnya agar lebih efisien dan profitable.

\section{Kendaraan Listrik (EV)}

Kendaraan listrik atau Electrical Vehicle (EV) merupakan kendaraan bermotor listrik berbasis baterai. Pemerintah Indonesia telah mengeluarkan dasar hukum untuk mendukung EV melalui Peraturan Presiden (Perpres) Nomor 55 Tahun 2019 tentang Percepatan Program Kendaraan Bermotor Listrik Berbasis Baterai untuk Transportasi Jalan. Namun, hal ini belum direspons oleh perusahaan untuk memproduksi kendaraan listrik. Hingga Januari 2020 jumlah kendaraan listrik yang terdaftar di DKI Jakarta hanya 699 unit. Perkembangan kendaraan listrik yang belum masif di Indonesia justru dapat dimanfaatkan menjadi peluang oleh PT XYZ untuk menyiapkan sarana dan fasilitas penunjang kendaraan listrik dimana PT XYZ dapat memanfaatkan lokasi dan jumlah SPBU yang strategis dan tersebar di DKI Jakarta \& Banten.

\section{Ancaman}

Ancaman masuknya pendatang baru

Untuk dapat mengoperasikan SPBU di DKI Jakarta \& Banten dibutuhkan biaya dan modal usaha yang cukup besar berkisar antara 20 s.d 40 miliar rupiah bergantung kepada luasan tanah dan kelengkapan sarana dan fasilitas SPBU. Namun jika pendatang baru memiliki modal dan kekuatan yang kuat untuk memenuhi persyaratan tersebut, maka ancaman masuknya pendatang baru menjadi ancaman bagi PTPR Sales Area II.

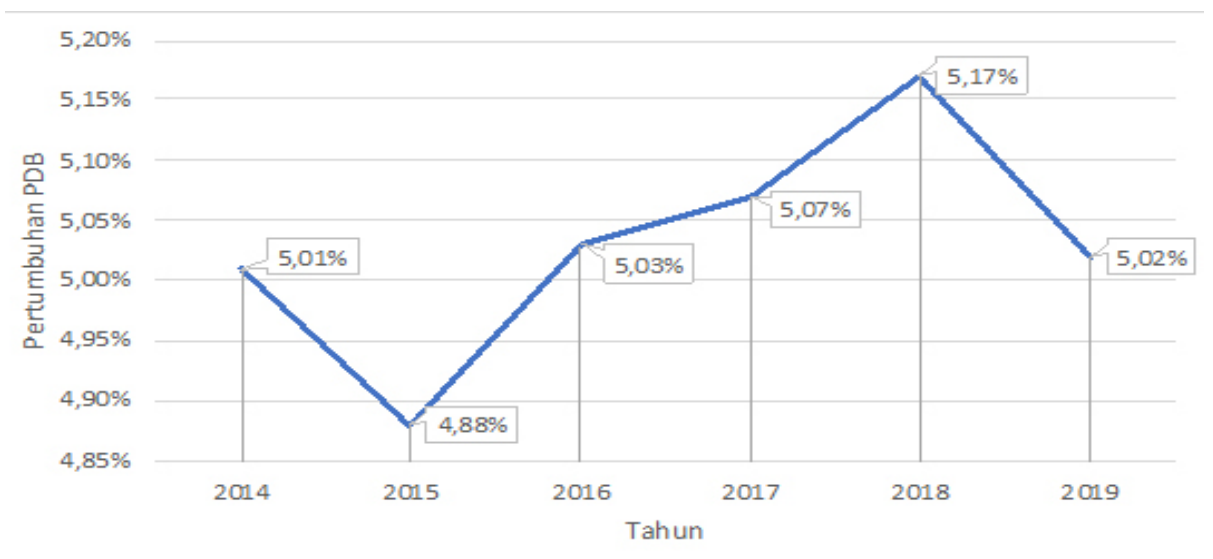

Gambar 4. Pertumbuhan ekonomi Indonesia tahun 2014-2019 (BPS, 2019) 
Persaingan antar Perusahaan dalam Industri

Secara total hingga Maret 2020 tercatat sudah ada lima perusahaan yang mengoperasikan SPBU di DKI Jakarta \& Banten. Shell memiliki SPBU terbanyak di DKI Jakarta \& Banten dengan 75 SPBU, disusul oleh PT XYZ, Total, BP-AKR, dan Vivo seperti ditunjukan pada Tabel 3. Pertumbuhan SPBU asing di DKI Jakarta $\&$ Banten yang cukup cepat menjadi ancaman nyata bagi PT XYZ dalam memperebutkan pangsa pasar.

Tabel 3. SPBU di DKI Jakarta \& Banten

\begin{tabular}{lc}
\hline Perusahaan & Jumlah SPBU (unit) \\
\hline Shell & 75 \\
PT XYZ & 46 \\
Total & 15 \\
BP-AKR & 5 \\
Vivo & 4 \\
\hline
\end{tabular}

Kenaikan Upah Minimum Provinsi

Upah Minimum Provinsi (UMP) adalah upah minimum yang berlaku untuk seluruh kabupaten/kota di satu provinsi. Provinsi DKI Jakarta \& Banten merupakan incaran para pencari kerja karena nilai UMP yang cukup besar. Setiap tahunnya, UMP naik sekitar 8-10\% setiap tahunya seperti ditunjukan pada Gambar 5. Kenaikan UMP pada setiap tahun tentunya berdampak terhadap biaya operasional dan lebih spesifiknya lagi biaya pekerja. Sedangkan margin penjualan BBM cenderung tidak berubah. Hal ini tentunya dapat menjadi ancaman bagi perusahaan pada masa yang akan datang yang harus diperhatikan.
Gaya hidup masyarakat

Masyarakat di DKI Jakarta \& Banten memiliki gaya hidup yang berbeda dibanding dengan masyarakat didaerah lainnya. Ketersediaan transportasi umum seperti Bis Antar kota, Busway Transjakarta, Kereta Commuter Line, dan yang terbaru ada Mass Rapid Transit (MRT) perlahan mengubah gaya hidup masyarakat dari menggunakan kendaraan pribadi menjadi menggunakan transportasi umum dalam berkegiatan sehari-hari. Hal ini tentu berdampak pada konsumsi BBM masyarakat yang frekuensinya pengisianya akan berkurang sehingga hal ini merupakan ancaman bagi PT XYZ.

Pandemi COVID-19

Indonesia dilanda pandemi COVID-19 sejak bulan Maret 2020. DKI Jakarta sebagai ibukota negara yang merupakan gerbang utama Indonesia menjadi provinsi paling terdampak. Pemerintah provinsi pun bergerak cepat dengan membuat kebijakan Pembatasan Sosial Berskala Besar (PSBB) yang membatasi aktivitas sosial warganya dimulai dari meliburkan kegiatan pendidikan hingga kegiatan perkantoran. Kebijakan ini tentunya sangat berdampak pada industri fuel retail di DKI Jakarta \& Banten dimana konsumsi BBM masyarakat menurun sehingga hal ini menjadi ancaman bagi PT XYZ.

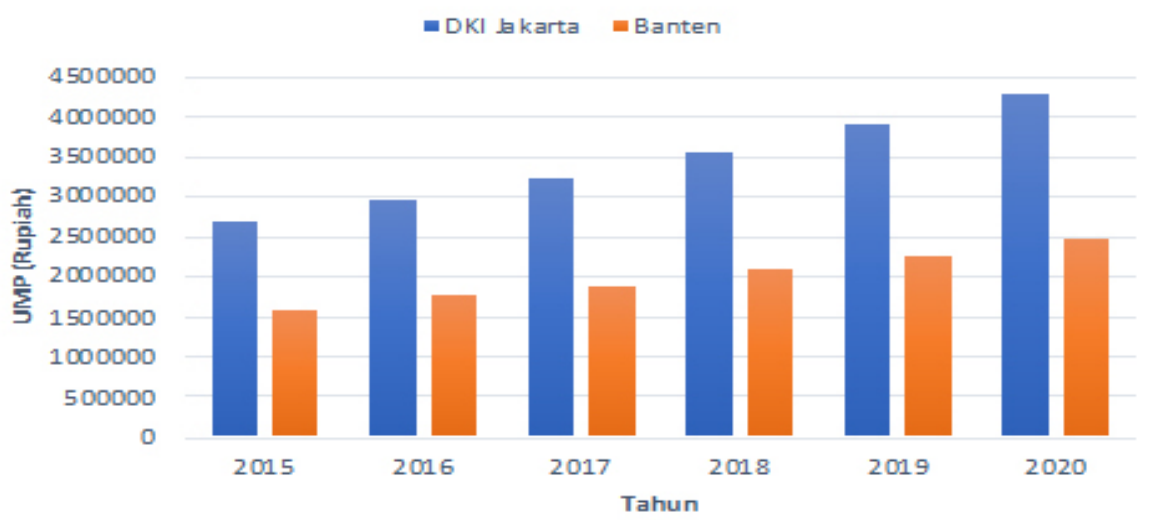

Gambar 5. UMP DKI Jakarta \& Banten tahun 2015-2020 (BPS DKI Jakarta \& Banten, 2020) 
Selain berdampak pada ekonomi masyarakat sekitar, SPBU juga memiliki dampak lingkungan yang cukup besar jika terjadi kebocoran dan pencemaran BBM hingga kebakaran. Ketertiban perizinan lingkungan, kondisi sarana dan fasilitas SPBU yang tidak terawat, dan pengoperasian SPBU yang tidak sesuai standar operasi menjadi faktor-faktor yang dapat menyebabkan dampak negatif SPBU terhadap lingkungan. Selain itu berbagai jenis kendaraan dan perilaku konsumen yang mengisi BBM di SPBU dapat menjadi faktor timbulnya kebakaran di SPBU. Jika hal ini tidak dimitigasi dengan baik maka akan menjadi ancaman bagi kelangsungan bisnis PT XYZ.

\section{Perizinan pembangunan SPBU}

Proses perizinan sangat berpengaruh dalam kelancaran pembangunan SPBU baru agar dapat beroperasi. Birokrasi yang panjang dan membutuhkan waktu yang lama menjadi faktor penentu dalam kelancaran perizinan SPBU. Selain izin operasi SPBU juga harus memenuhi izin lingkungan. Menurut Undang-Undang Republik Indonesia Nomor 32 Tahun 2009 syarat utama penyelenggara usaha yang berdampak pada lingkungan adalah Analisis Dampak Lingkungan (AMDAL) dan Upaya Pemantauan Lingkungan Hidup (UKL-UPL). Tentunya hal ini menjadi ancaman bagi PT XYZ karena berpotensi menghambat pertumbuhan jumlah SPBU.

\section{Evaluasi Faktor Eksternal}

Evaluasi faktor eksternal digunakan untuk mengukur seberapa besar respons perusahaan terhadap peluang dan ancaman yang sedang terjadi. Peluang harus dimanfaatkan perusahaan sedangkan ancaman harus dihindari. Adapun hasil evaluasi faktor eksternal PT XYZ terdapat pada Tabel 4. Total skor pada matriks EFE adalah 2,64, skor tersebut lebih besar dari skor rata-rata yaitu 2,50. Hal tersebut menunjukkan bahwa perusahaan saat ini cukup mampu dalam memanfaatkan peluang yang ada dan mengatasi ancaman yang muncul.

\section{Analisis Matriks Internal-Eksternal}

Setelah dilakukan evaluasi terhadap faktor internal (IFE) dan faktor eksternal (EFE) pada perusahaan kemudian dilakukan pemetaan terhadap hasil tersebut matriks internal-eksternal (IE). Adapun total nilai IFE yang diperoleh masuk dalam kategori posisi internal sedang yaitu dan total nilai EFE juga masuk dalam kategori posisi eksternal sedang dengan nilai seperti ditunjukan pada Gambar 6. Berdasarkan hasil evaluasi internal dan eksternal tersebut didapatkan hasil bahwa PT XYZ masuk ke dalam sel kuadran V yaitu menjaga dan mempertahankan (hold and maintain). Adapun menurut David (2013) strategi yang dapat diterapkan dalam posisi ini adalah pengembangan produk dan penetrasi pasar. Strategi pengembangan produk bertujuan untuk meningkatkan penjualan dengan cara memperbaiki atau melakukan modifikasi pada produk dan jasa yang sudah ada. sementara strategi penetrasi pasar bertujuan untuk meningkatkan pangsa pasar dengan barang dan jasa yang dimiliki PT XYZ saat ini.

Tabel 4. Matriks External Factor Evaluation (EFE) PT XYZ

\begin{tabular}{lccc}
\hline Faktor Eksternal Strategis & Bobot & Peringkat & Skor \\
\hline Peluang (Opportunity) & & & \\
Program Sinergi BUMN & 0,16 & 2 & 0,31 \\
Tingkat pertumbuhan ekonomi & 0,14 & 2 & 0,28 \\
Industri 4.0 & 0,17 & 3 & 0,48 \\
Electric Vehicle & 0,18 & 2 & 0,36 \\
Ancaman (Threat) & & & \\
Kenaikan Upah Minimum Provinsi (UMP) & 0,12 & 4 & 0,47 \\
Pandemi COVID-19 & 0,08 & 3 & 0,24 \\
Dampak SPBU terhadap lingkungan & 0,09 & 3 & 0,26 \\
Persaingan antar perusahaan dalam industri fuel retail & 0,08 & 3 & 0,24 \\
\hline Total Skor EFE & 2,64 & & \\
\hline
\end{tabular}




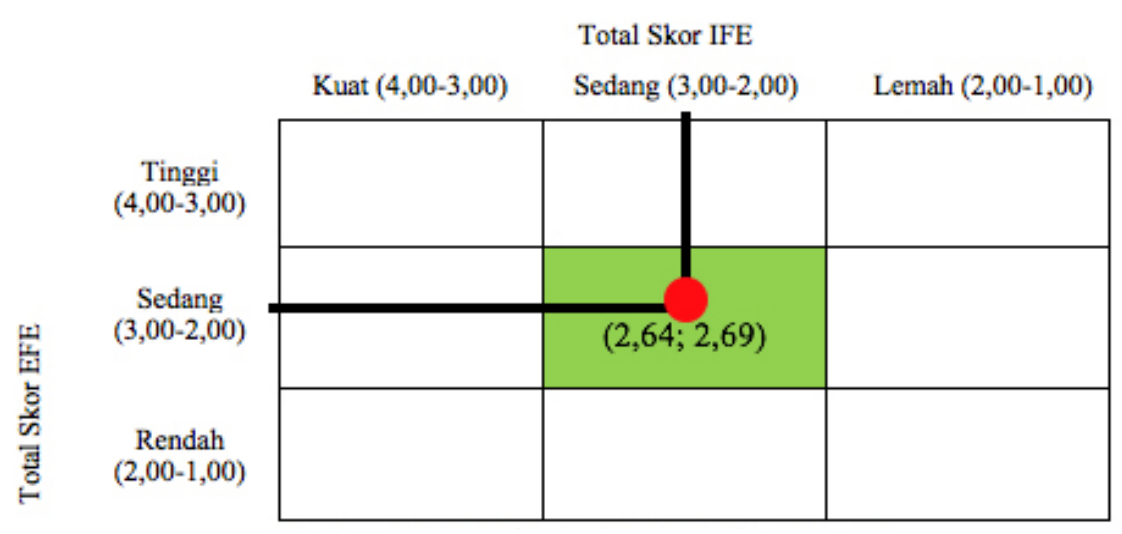

Gambar 6. Matriks IE PT XYZ

\section{Analisis SWOT}

Analisis Strengths, Weakness, Opportunities, dan Threats (SWOT) digunakan untuk merumuskan strategi alternatif yang mengacu pada pengembangan strategi yang dihasilkan oleh matriks IE, terdiri dari 6 strategi pengembangan produk yaitu (1) meningkatkan Quality \& Quantity (QnQ) diatas standar Pertamina agar single margin berada pada nilai tertinggi, (2) mengganti conveniencestore yang merugi dengan mengembangkan food\&beverages vending machine di area pulau pompa, (3) membuat sistem automasi pengontrol utang piutang, (4) meningkatkan transaksi cashless dan self service, (5) memastikan keandalan SPBU, (6) menetapkan batas aman outstanding piutang, dan 3 strategi penetrasi pasar, yaitu (1) memanfaatkan sinergi BUMN dan pertumbuhan ekonomi untuk meningkatkan konsumen B2B dengan sistem pembayaran MyPertamina dan RFID, (2) Memanfaatkan jaringan SPBU dan modal investasi untuk konsep SPBU Flagship 4.0, (3) Menjalin kerja sama operasi dengan convenience store yang berpengalaman. Hasil perumusan strategi tersebut terdapat pada Tabel 5.

\section{Implikasi Manajerial}

Implikasi manajerial dari penelitian ini diwujudkan dalam rekomendasi strategi bisnis dari matriks SWOT yang dijabarkan ke dalam rencana kegiatan strategik dalam jangka waktu 2 tahun (2020-2022) berdasarkan 9 strategi alternatif hasil matriks SWOT. Urutan prioritas strategi yang akan dijalankan didapatkan berdasarkan interview narasumber internal.

Prioritas strategi pertama adalah meningkatkan Quality \& Quantity $(Q n Q)$ di atas standar Pertamina agar single margin berada pada nilai tertinggi, dimulai pada semester kedua tahun 2020 dengan cara memastikan SPBU lolos audit PASTI PAS dan PASTI PRIMA setiap bulannya dan monitoring untuk meningkatkan penjualan bahan bakar non subsidi. Prioritas strategi kedua adalah memanfaatkan sinergi BUMN dan pertumbuhan ekonomi untuk meningkatkan konsumen business to business (B2B) dengan sistem pembayaran MyPertamina dan RFID dengan memastikan keandalan sistem pembayaran MyPertamina dan RFID di SPBU PT XYZ. Harapannya jika keandalan sistem pembayaran di SPBU terjaga dengan baik maka konsumen $B 2 B$ terutama BUMN akan meningkat.

Prioritas strategi ketiga adalah memastikan keandalan SPBU dengan cara simplifikasi proses pengadaan perawatan SPBU. Simplifikasi birokrasi pada proses pengadaan harus dibuat sesimpel mungkin untuk menjaga keandalan SPBU agar tetap terjaga dengan baik. Selain itu diperlukan juga monitoring \& preventive maintenance agar ada mitigasi perawatan dari setiap peralatan yang digunakan di SPBU. Prioritas strategi keempat adalah meningkatkan transaksi cashless dan self service dengan cara memastikan keandalan dan variasi sistem pembayaran cashless di SPBU dan memastikan keamanan transaksi self service di SPBU. Prioritas strategi kelima adalah menghindari saldo piutang outstanding yang tinggi dengan mapping dan menentukan batas aman piutang outstanding dan menetapkan aturan yang tegas untuk klien yang memiliki outstanding tinggi sehingga arus kas perusahaan tidak terganggu. Prioritas strategi keenam adalah membuat sistem automasi pengontrol utang piutang. Dimulai dengan merancang algoritma dan mengimplementasikan algoritma pada sistem automasi pengontrol utang piutang. 


\begin{tabular}{|c|c|c|}
\hline Faktor Eksternal & $\begin{array}{l}\text { Kekuatan (Strength) } \\
\text { 1. Lokasi dan jumlah SPBU } \\
\text { 2. Brand Pertamina } \\
\text { 3. Sistem pembayaran menggunakan } \\
\text { MyPertamina dan RFID } \\
\text { 4. Tersedia car wash di beberapa SPBU } \\
\text { 5. Jaminan Quality \& Quantity (QnQ) } \\
\text { 6. Modal (Equity) dari Pertamina } \\
\text { (Persero) } \\
\text { 7. Kebijakan single margin dari PT } \\
\text { Pertamina (Persero) }\end{array}$ & $\begin{array}{l}\text { Kelemahan (Weakness) } \\
\text { 1. Lemahnya pengelolaan } \\
\text { convenience store. } \\
\text { 2. Budaya kerja perusahaan kurang } \\
\text { baik. } \\
\text { 3. Kapabilitas pekerja kurang baik. } \\
\text { 4. Organisasi yang tidak efektif } \\
\text { 5. Lemahnya kemampuan collecting } \\
\text { piutang }\end{array}$ \\
\hline $\begin{array}{l}\text { Peluang (Opportunity) } \\
\text { 1. Program sinergi BUMN } \\
\text { 2. Tingkat pertumbuhan ekonomi } \\
\text { 3. Industri } 4.0 \\
\text { 4. Electric Vehicle }(\mathrm{EV})\end{array}$ & $\begin{array}{l}\text { Strategi SO } \\
\text { 1. Meningkatkan Quality \& Quantity } \\
\text { (QnQ) diatas standar Pertamina } \\
\text { agar single margin berada pada nilai } \\
\text { tertinggi (S2, S5, S7. O2) } \\
\text { 2. } \text { Memanfaatkan sinergi BUMN } \\
\text { dan pertumbuhan ekonomi untuk } \\
\text { meningkatkan konsumen B2B dengan } \\
\text { sistem pembayaran MyPertamina dan } \\
\text { RFID (O1, O2, S1, S3) } \\
\text { 3. Memanfaatkan jaringan SPBU dan } \\
\text { modal investasi untuk konsep SPBU } \\
\text { Flagship } 4.0(S 1, S 4, S 6, O 3, O 4)\end{array}$ & $\begin{array}{l}\text { Strategi WO } \\
\text { 1. Mengganti convenience } \\
\text { store yang merugi } \\
\text { dengan mengambangkan } \\
\text { food\&beverages vending } \\
\text { machine di area pulau pompa } \\
\text { (W1, W2, W3, O3) } \\
\text { 2. Membuat sistem automasi } \\
\text { pengontrol utang piutang (W4, } \\
\text { W5, O3) }\end{array}$ \\
\hline $\begin{array}{l}\text { Ancaman (Threat) } \\
\text { 1. Kenaikan Upah Minimum } \\
\text { Provinsi (UMP) } \\
\text { 2. Pandemi COVID-19 } \\
\text { 3. Dampak SPBU terhadap } \\
\text { lingkungan } \\
\text { 4. Persaingan antar perusahaan } \\
\text { dalam industri fuel retail }\end{array}$ & $\begin{array}{l}\text { Strategi ST } \\
\text { 1. Meningkatkan transaksi cashless dan } \\
\text { self service (S3, S5, S6, T1, T2) } \\
\text { 2. Memastikan keandalan SPBU (S2, } \\
\text { S5, S6, T3, T4) }\end{array}$ & $\begin{array}{l}\text { Strategi WT } \\
\text { 1. Menjalin kerja sama operasi } \\
\text { dengan convenience store yang } \\
\text { berpengalaman ( } W 1, W 3, W 4, T 1 \text {, } \\
\text { T4) } \\
\text { 2. Menetapkan batas aman } \\
\text { outstanding piutang (W2, W5, } \\
\text { T1) }\end{array}$ \\
\hline
\end{tabular}

Catatan: Bold (Strategi Pengembangan Produk); Italic (Strategi Penetrasi Pasar)

Prioritas strategi ketujuh adalah mengganti convenience store yang merugi dengan mengembangkan food \& beverages vending machine di area pulau pompa. Dimulai dengan pemilihan vendor vending machine yang sesuai standar HSSE SPBU, selanjutnya melakukan penutupan convenience store yang merugi dan menggantinya dengan food \& beverages vending machine di area pulau pompa. Prioritas strategi kedelapan adalah menjalin kerja sama operasi dengan convenience store yang berpengalaman dengan cara pemilihan kandidat partner operasi dan memulai kerja sama operasi convenience store yang merugi. Prioritas strategi yang terakhir adalah memanfaatkan jaringan SPBU dan modal investasi untuk konsep SPBU Flagship 4.0. Dimulai dengan pembuatan rancangan konsep dan feasibility study SPBU Flagship 4.0. Kemudian dilakukan pemilihan dan pelaksanaan renovasi SPBU yang cocok untuk konsep SPBU Flagship 4.0.

\section{KESIMPULAN DAN SARAN}

\section{Kesimpulan}

Dari hasil analisis faktor lingkungan internal dan eksternal yang telah dilakukan terdapat beberapa faktor internal yang terdiri dari 7 kekuatan dan 5 kelemahan perusahaan yang dimiliki PT XYZ, serta didapatkan faktor eksternal strategis yang terdiri dari 4 peluang dan 4 ancaman yang memengaruhi bisnis PT XYZ. PT XYZ berada pada kuadran V dalam matriks IE. Sehingga didapatkan 9 strategi alternatif yang dapat diterapkan untuk bisnis PT XYZ, terdiri dari 6 strategi pengembangan produk dan 3 strategi penetrasi pasar.

\section{Saran}

Saran yang dapat diberikan berdasarkan penelitian adalah PT XYZ harus segera membenahi kelemahan perusahaan yang telah dikemukakan terutama 
yang berkaitan dengan sumber daya manusia, agar perusahaan dapat berjalan lebih baik lagi. PT XYZ juga harus berani melakukan terobosan dengan menerapkan strategi alternatif yang sifatnya baru di industri fuel retail seperti pengembangan food\&beverages vending machine dan konsep SPBU 4.0. Pengembangan ini dapat menjawab keinginan konsumen dan menjadi diferensiasi bagi SPBU PT XYZ dengan SPBU lainya. Setelah adanya implementasi strategi, dapat dilakukan penelitian lanjutan tentang analisis pengaruh atas implementasi strategi tersebut terhadap perubahan kinerja perusahaan.

\section{DAFTAR PUSTAKA}

[BPS] Badan Pusat Statistik. 2019. Perkembangan jumlah kendaraan bermotor menurut jenis tahun 1949-2019. https://www.bps.go.id/ linkTableDinamis/view/id/1133. [3 Desember 2020].

[BPS] Badan Pusat Statistik. 2019. Pertumbuhan ekonomi Indonesia triwulan IV-2019. https:// www.bps.go.id. [3 Desember 2019].

Bumpass D, Ginn V, Tuttle MH. 2015. Retail and wholesale gasoline price adjustments in response to oil price changes. Energy Economics 52:4954. https://doi.org/10.1016/j.eneco.2015.08.030

Davis LW, McRae S, Bejarano ES. 2019. An economic perspective on Mexico's nascent deregulation of retail petroleum markets. Economics of Energy \& Environmental Policy 8(2). https://doi. org/10.5547/2160-5890.8.2.1dav

David F. 2013. Strategic Management: Concept and Cases. Ed. ke-14. London: Pearson Education Limited.

Frederico GF, Garza-Reyes JA, Anosike A, Kumar V. 2019. Supply chain 4.0: Concepts, maturity and research agenda. Supply Chain Managemen 24(2):262-282. https://doi.org/10.1108/SCM09-2018-0339
Ghobakhloo M. 2018. The future of manufacturing industry: A strategic roadmap toward Industry 4.0. Journal of Manufacturing Technology Management 29(6):910-936. https://doi. org/10.1108/JMTM-02-2018-0057

Gregoric M. 2014. PESTEL Analysis of Tourism Destinations in The Perspective of Businnes Tourism (MICE). In Faculty of Tourism and Hospitality Management in Opatija. Biennial International Congress. Tourism \& Hospitality Industry 551-565.

Haucap J, Heimeshoff U, Siekmann M. 2017. Fuel prices and station heterogeneity on retail gasoline markets. The Energy Journal 38(6):81-103. https://doi.org/10.5547/01956574.38.6.jhau

Knott PJ. 2009. Integrating resource-based theory in a practice-relevant form. Journal of Strategy and Management 2(2):163-174. https://doi. org/10.1108/17554250910965317

Ma'ruf A. 2005. Analisis penawaran dan permintaan BBM (Studi kasus di Propinsi Daerah Istimewa Yogyakarta. Jurnal Ekonomi dan Studi Pembangunan (JESP) 6(1):1-20.

Porter ME. 1998. Competitive Strategy: Techniques for Analyzing Industries and Competitors with A New introduction. New York: Free Press.

Sugiyono. 2017. Metode Penelitian: Kuantitatif, Kualitatif, dan R\&D. Bandung: Alfabeta.

Wicaksono T, Syarief R, Jahroh S. 2020. Strategi pengembangan bisnis pada industri otomotif. Jurnal Aplikasi Manajemen dan Bisnis (JABM) 6(2):229-241.https://doi.org/10.17358/ jabm.6.2.229

Yilmazkuday D, Yilmazkuday H. 2019. Redistributive effects of gasoline prices. Networks and Spatial Economics 19(1):109-124. https://doi. org/10.1007/s11067-018-9435-9

Yüksel İ. 2012. Developing a multi-criteria decision makingmodel forPESTELanalysis. International Journal of Business and Management 7(24):5266. https://doi.org/10.5539/ijbm.v7n24p52 